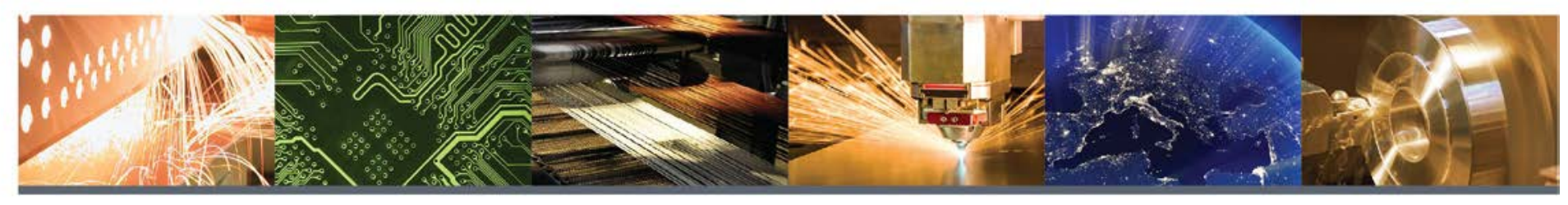

\title{
Cost Modelling for Energy Efficient Window Replacements
}

James McCall, Ran Fu, Rob Tenent, and Margaret Mann

National Renewable Energy Laboratory

CEMAC is operated by the Joint Institute for Strategic Energy Analysis for the U.S. Department of Energy's Office of Energy Efficiency and Renewable Energy.

Technical Report

NREL/TP-6A50-70967

April 2019

Contract No. DE-AC36-08GO28308 


\section{Cost Modelling for Energy Efficient Window Replacements}

James McCall, Ran Fu, Rob Tenent, and Margaret Mann

National Renewable Energy Laboratory

Prepared under task number BLDG.10136.95.20.00

CEMAC is operated by the Joint Institute for Strategic Energy Analysis for the U.S. Department of Energy's Office of Energy Efficiency and Renewable Energy.

Clean Energy Manufacturing Analysis Center 15013 Denver West Parkway Golden, CO 80401 303-275-3000 www.manufacturingcleanenergy.org
Technical Report

NREL/TP-6A50-70967

April 2019

Contract No. DE-AC36-08GO28308 


\section{NOTICE}

This work was authored by the National Renewable Energy Laboratory, operated by Alliance for Sustainable Energy, LLC, for the U.S. Department of Energy (DOE) under Contract No. DE-AC36-08GO28308. Funding provided by the U.S. Department of Energy Office of Energy Efficiency and Renewable Energy Building Technologies Office. The views expressed in the article do not necessarily represent the views of the DOE or the U.S. Government. The U.S. Government retains and the publisher, by accepting the article for publication, acknowledges that the U.S. Government retains a nonexclusive, paid-up, irrevocable, worldwide license to publish or reproduce the published form of this work, or allow others to do so, for U.S. Government purposes.

This report is available at no cost from the National Renewable Energy Laboratory (NREL) at www.nrel.gov/publications.

U.S. Department of Energy (DOE) reports produced after 1991 and a growing number of pre-1991 documents are available free via www.OSTI.gov.

Cover Photos (left to right): iStock 2225189; iStock 16687273; Oak Ridge National Laboratory; iStock 24304597; iStock 26005993; iStock 2069560.

NREL prints on paper that contains recycled content. 


\section{List of Acronyms}

AAMA

BLS

BTO

CEMAC

DOE

EEBC

EPA

EWC

IG

LBNL

NFRC

NREL

PII

PV

SETO

SG\&A

SHGC

WDDA
American Architectural Manufacturers Association Bureau of Labor Statistics Building Technologies Office Clean Energy Manufacturing Analysis Center U.S. Department of Energy Energy Efficiency Building Coalition U.S. Environmental Protection Agency Efficient Windows Collaborative insulating glass Lawrence Berkeley National Laboratory National Fenestration Rating Council National Renewable Energy Laboratory personally identifiable information photovoltaic

Solar Energy Technologies Office sales, general, and administrative expenses Solar Heat Gain Coefficient Window and Door Dealers Alliance 


\section{Main Findings}

- Overall, the window replacement industry is competitive, and adoption is differentiated on total installed cost and customer acquisition strategies.

- The analysis did not identify any single approach for reducing window replacement cost. Cost-reduction efforts will need to focus on new, cheaper window products and manufacturing techniques and the reduction of upfront customer acquisition costs through educating consumers.

- On average, window hardware costs made up roughly $55 \%$ of the total installed cost, with soft costs (e.g., labor, permitting, shipping, and customer acquisition costs) making up the remaining total cost.

- The average cost for window replacement observed from real-life invoices and cost modeling was around $\$ 600$ per window. Cost variation seen from real-life window invoices was $\$ 200$ - $\$ 980$ per window replacement.

- Data collected from invoices and other real installation costs were $15 \%-20 \%$ higher than insurance industry standard cost estimation models. This difference led to several installers avoiding insurance replacements due to lower job compensation.

- Outside of reduction in upfront customer acquisition costs, window industry members identified three education areas that could increase window replacement with more efficient windows:

- Consumer education - reduces upfront customer acquisition costs and provides a consistent message across the industry for credibility

- Communication of window replacement benefits and trade-offs - allows for consumers to make rational investment decisions and reduces upfront customer acquisition costs

- Increased ease of quality window product identification and installation certifications - allows consumers to know they are getting a good product that is installed correctly for maximum energy efficiency benefits; education in this area could reduce "decision paralysis" during the customer-acquisition process. 


\section{Table of Contents}

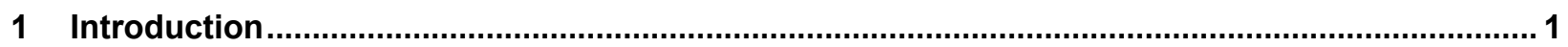

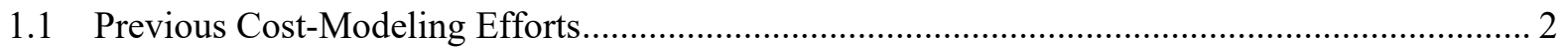

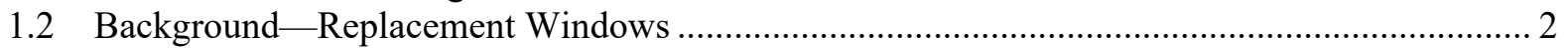

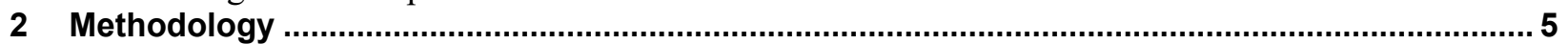

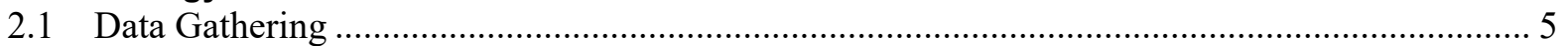

2.1.1 Professional Estimation Software …............................................................ 5

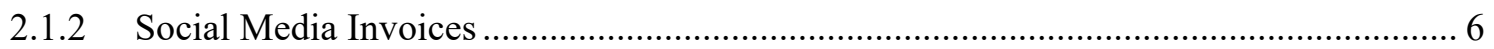

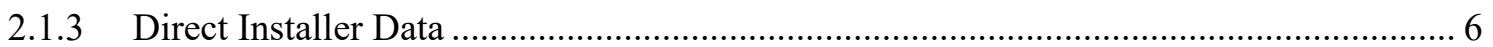

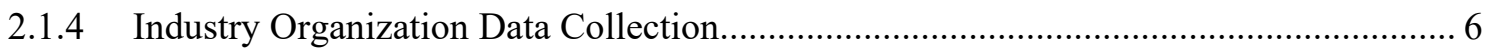

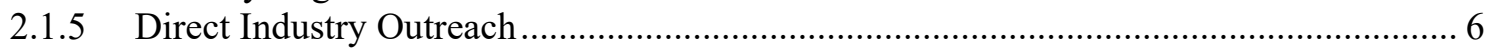

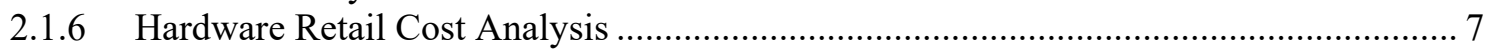

2.2 Results From a Top-Down Cost-Modeling Data Analysis................................................... 7

2.3 Key Learnings From the Industry Roundtable Meeting ................................................. 9

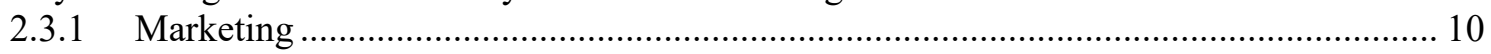

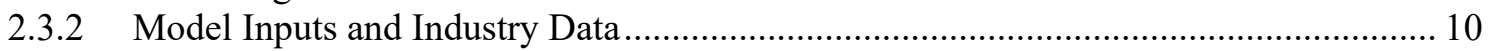

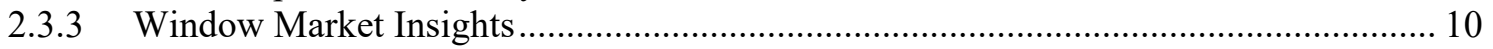

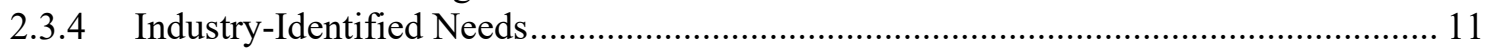

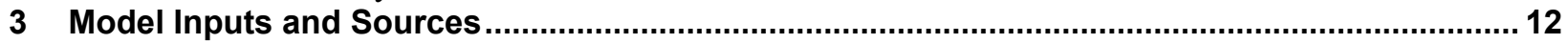

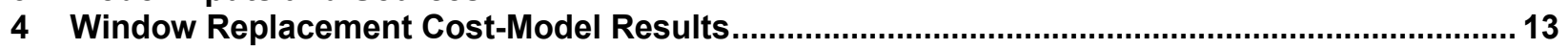

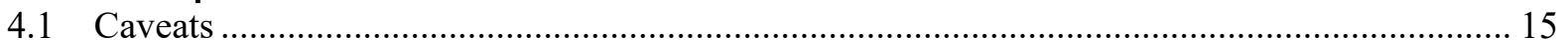

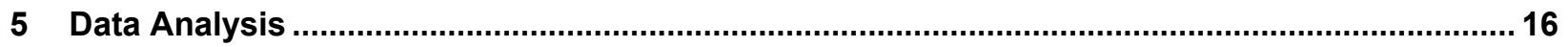

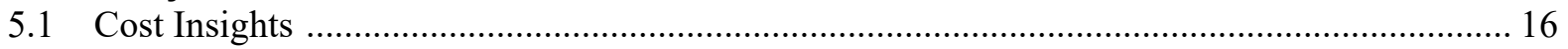

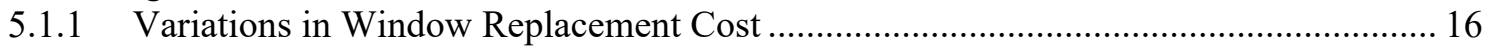

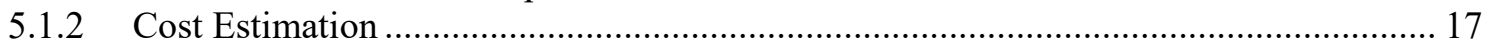

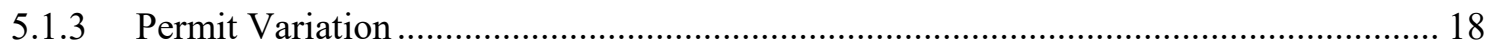

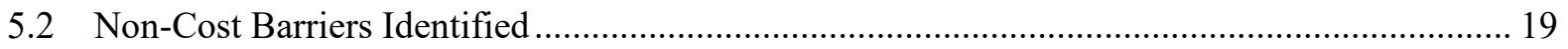

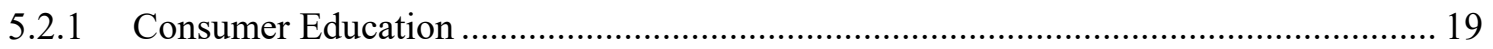

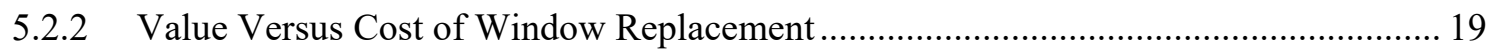

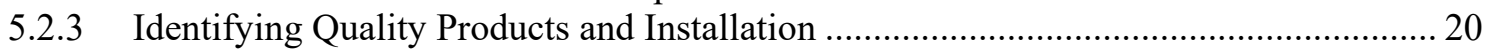

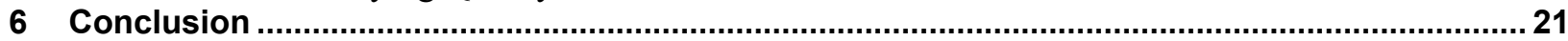

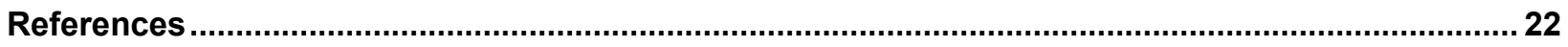

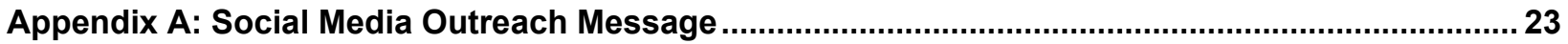

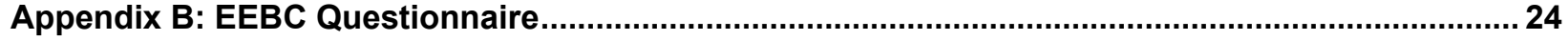

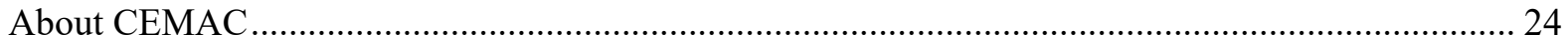

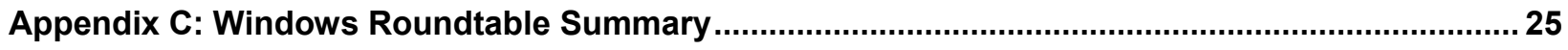

Windows Roundtable Discussion Writeup............................................................................... 25

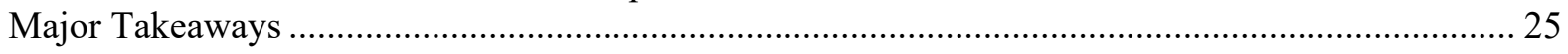




\section{List of Figures}

Figure 1. Window replacement value chain...................................................................................... 1

Figure 2. Window diagram of a double-hung window (Grant Communications 2017) ............................ 3

Figure 3. Pocket insert replacement window diagram (Pella 2017b) .................................................... 3

Figure 4. Full-frame window replacement diagram (Pella 2017a) ....................................................... 4

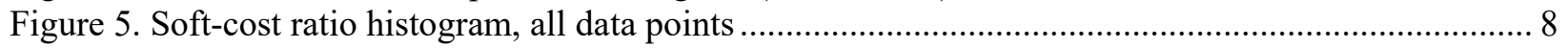

Figure 6. Soft-cost ratio histogram, estimation programs excluded .................................................. 9

Figure 7. Cost drivers, modeled cost categories, inputs, and outputs of window replacement cost model 14

Figure 8. Installed cost per project for a small installer, by cost category ........................................... 15

Figure 9. Building permit cost for different municipalities for a $\$ 5,000$ project .................................. 18

\section{List of Tables}

Table 1. Price Per Window and Soft-Cost Ratio of Data Collected ........................................................ 8

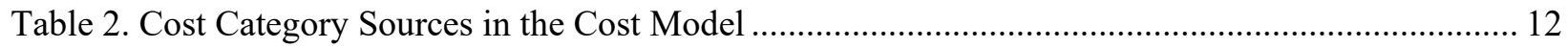




\section{Introduction}

In support of the Building Technologies Office's (BTO's) mission of increasing the penetration of energy efficienct products, the National Renewable Energy Laboratory (NREL) collected data and performed cost modeling to understand the total installed cost of energy efficient residential window replacements. As of 2016, residential window replacements make up roughly $40 \%$ of the window sales market and represent an important market for window manufacturers and installers (Catalina Research, Inc. 2016). The main project objective was to evaluate the contribution of hardware and non-hardware costs to the total installed cost of energy efficient replacement windows and determine the key drivers that contribute to variations in soft costs of replacement windows.
Manufacturing markup
Dealer markup
Installation labor, overhead, and profit

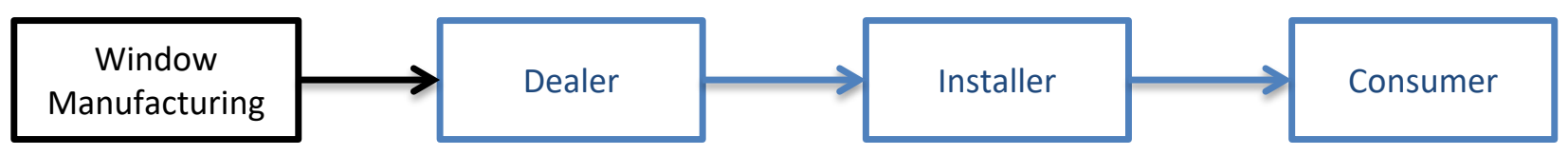

Figure 1. Window replacement value chain

This analysis created a bottom-up cost model that combined multiple data collection approaches and sources to determine the main cost drivers for window replacement projects. Currently, the window industry is perceived by many as lacking transparency of installed costs, so this research builds on past analyses that detail manufactured cost of windows and fills in the remaining nonhardware costs (hereafter referred to as soft costs) to consumers. To fill this gap, cost-modeling efforts evaluated costs incurred after window products leave the manufacturer and include all steps in blue in Figure 1. Window manufacturing costs from previous analyses performed by Lawrence Berkeley National Laboratory (LBNL) are included in our results but were not further studied. After initial data collection and cost modeling, our cost model was validated by installers in the windows industry, previous project invoices, and comparison with cost estimation tools.

Soft-cost categories can be variable depending on the industry being considered. For the sake of this report, soft costs for window replacement include: dealer profit; installation labor; labor overhead and profit; sales, general, and administrative (SG\&A) expenses; shipping; state sales tax; permit cost (where applicable); and contingency. These costs represent the total observed costs from window manufacturers to the consumer. Soft costs for replacement windows will be mostly comparable to new window installation, but labor costs will likely be higher for replacement windows due to removal of the old windows and dealing with anomalies in the window openings.

This report first discusses previous cost-modeling efforts in the solar industry that provide the basic methodology for our cost model. Next, this report covers background information of the window replacement industry to establish common terms. Then, this report covers the methodology, data collection, and results of data gathering used in the creation of the cost model. Next, model inputs and results of the final cost model are discussed. Finally, this report discusses non-cost drivers that affect the window replacement industry. 


\subsection{Previous Cost-Modeling Efforts}

The basic cost-modeling efforts for this project build on research performed by Fu et al. (2016) to benchmark the cost of solar photovoltaic (PV) systems in the United States. This research used a bottom-up cost-modeling analysis to capture all system costs associated with solar installations, including project development, hardware, and installation costs. Costs incurred to the project developer included in this modeling effort were: component costs (module, inverter, and balance-of-system hardware), soft costs (land acquisition, overhead, net profit, sales tax, permitting, inspection, and interconnection), and labor costs (direct plus indirect labor expenses). This Fu et al. 2016 methodology was re-created in this project to capture all costs along the value chain of window replacement from manufacturing to the consumer. The Fu et al. (2016) study found that soft costs of PV installations made up roughly $55 \%$ of the final cost. At the time of publication, a large portion of the Solar Energy Technologies Office's (SETO's) funding was directed to the hardware costs of $\mathrm{PV}$, and insight from this analysis led to a shift in funding to address soft costs.

Along with Fu et al.'s (2016) work, LBNL previously modeled the manufacturing cost components of energy efficient windows. In working with industry partners, LBNL compiled the cost of manufacturing for different window options (e.g., frame, glass, gas-fill, coatings, and insulating glass [IG] units). The manufacturing prices reported in the LBNL model were direct inputs into NREL's cost model as the cost of manufactured windows to window dealers. $D+R$ International ${ }^{1}$ performed an analysis of window prices to builders in Canada that compiled total window price and performance metrics (e.g., U-value and Solar Heat Gain Coefficient [SHGC]). Their analysis did not find a correlation between energy efficiency metrics and window price, leading to some difficulties in cost comparison between window brands. This price to dealers was used to establish the markup costs from manufacturers to dealers when compared with the LBNL manufacturing cost analysis.

\subsection{Background - Replacement Windows}

According to industry members, there is some confusion about the terminology associated with window replacement products. In talks with industry and the U.S. Department of Energy (DOE), we determined it was important to define the different replacement options in relation to costmodeling efforts.

- A glass only replacement is when the existing window frame is left intact and the glass itself is either repaired or replaced with an IG unit. A similar replacement to a glass only replacement is a sash replacement, which is when one of the window units in a single and double hung window unit is replaced only and the frame is kept intact (see the window diagram in Figure 2). This replacement is the cheapest of all the options and requires the least amount of time but does not address existing installed conditions.

\footnotetext{
${ }^{1}$ https://www.drintl.com/
} 


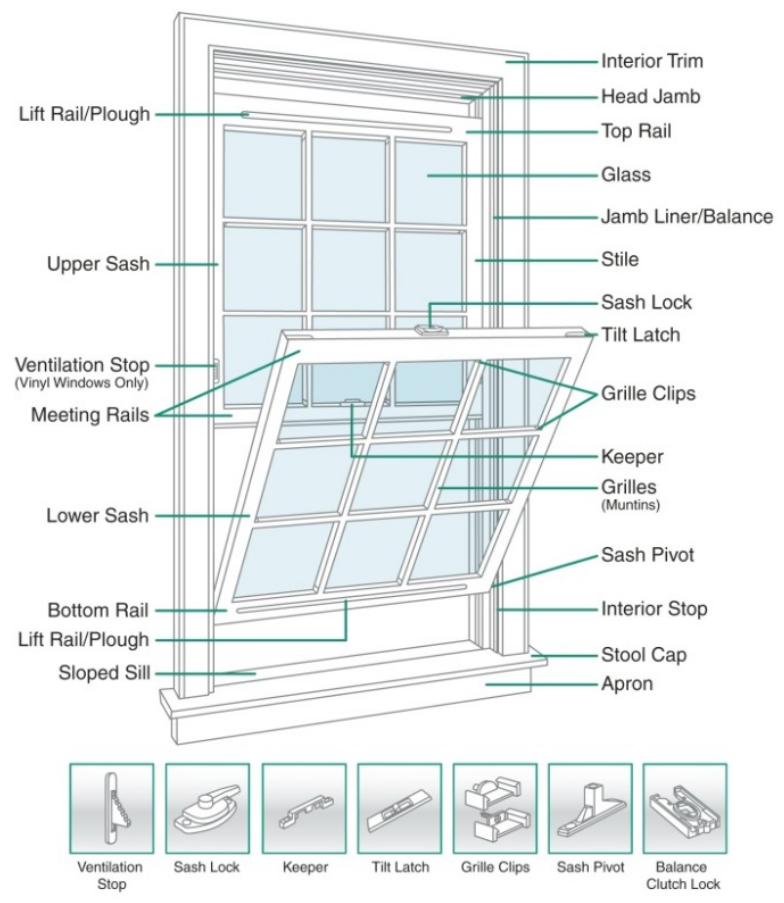

Figure 2. Window diagram of a double hung window (Grant Communications 2017)

- A pocket insert window replacement is a unit designed to be installed inside an existing window frame. This is a mid-price option available and requires minimal installation time compared to a full frame replacement. The pocket insert replacement allows for replacement of the entire window component but does not impact the initial frame and window opening. The downsides of this option are a reduction in the current window glass area and lack of addressing potential issues with the existing frame, such as rot or poor original installation techniques.

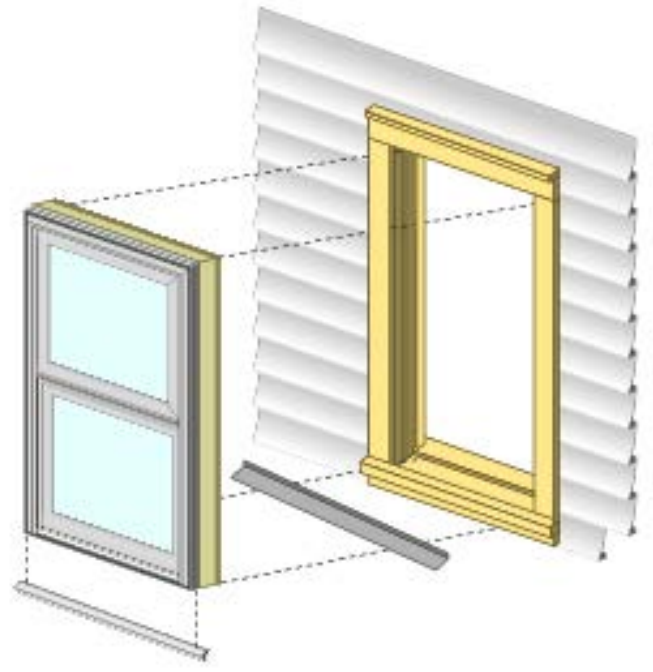

Figure 3. Pocket insert replacement window diagram (Pella 2017b) 
- A full-frame window replacement removes the previous window entirely and takes the window opening down to the rough window opening or brick mold casing. This replacement is more labor intensive than a pocket insert replacement but allows for inspection of the window frame and original installation practices. This option has the potential for the highest energy savings because it allows for proper air sealing between the window and the rest of building envelope, but this must be balanced with increased installation costs.

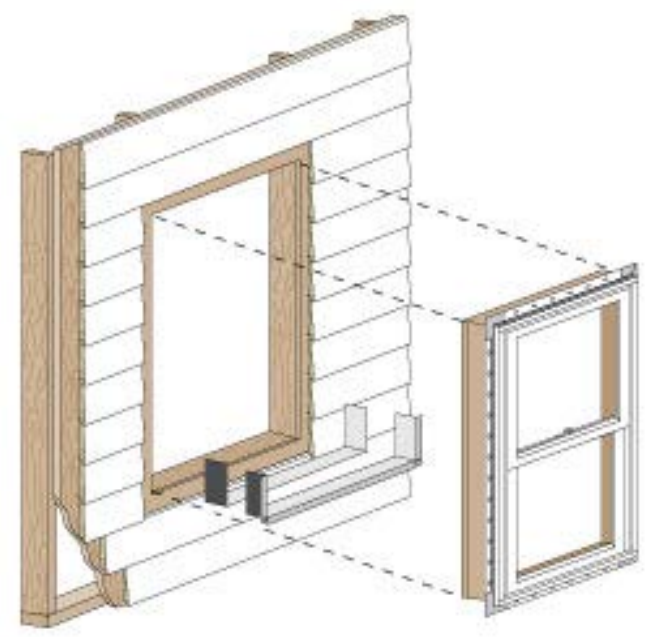

Figure 4. Full-frame window replacement diagram (Pella 2017a)

For the sake of the cost-modeling effort, NREL focused on a vinyl, pocket insert window replacement into an existing wood frame. Vinyl windows cover roughly $75 \%$ of the window replacement market as of 2016 (Catalina Research, Inc. 2016) and represent a large market share of window replacements, indicated by several installers. The pocket insert window represents a large portion of the replacement window market, according to discussions with installers. Labor costs for a full-frame window replacement would be higher due to removal of the existing frame, but cost data on this option were not collected during analysis. 


\section{Methodology}

\subsection{Data Gathering}

Several different sources were utilized for data collection of individual cost components for window replacements. Overall installed costs were also collected when available to validate the cost model. The different data sources utilized were: (1) professional estimation software currently used by the window replacement and insurance industries, (2) collection of actual window invoices through social media platforms, (3) direct installer invoice collection, (4) surveys of window replacement industry organization members, (5) direct contact with past industry members, and (6) a retail cost analysis of several online window suppliers.

The LBNL cost model was used to establish the manufactured window cost to dealers, but the price of the window to consumers has associated markup from the dealer to installers. To capture this markup, our analysis will use differences in retail prices from the cost to dealers obtained from two sources: a $\mathrm{D}+\mathrm{R}$ analysis of window prices in Canada for new construction and information obtained from online window retailers (Home Depot and Lowes). Online construction and home improvement websites (Angie's List, the Better Business Bureau, and Apartment Therapy) were used to identify total window replacement costs and to look for cost drivers identified by consumers.

The remainder of this section will discuss new data sources that NREL compiled for the cost model.

\subsubsection{Professional Estimation Software}

Three construction estimation programs were utilized for data collection during this project: Craftsmen, Xact Remodel, and RS Means. Each model provided different data that was used for modeling efforts. A brief background on each tool and what data were incorporated into the final model are provided below.

\subsubsection{Craftsmen}

The Craftsmen National Estimation Tool provided data on window retail costs, labor time, labor cost, and crew size/make up. No other soft costs are included in the tool, but bare labor costs from this tool validated labor productivity rates within the final project model.

\subsubsection{Xact Remodel}

The Xact Remodel tool was developed by Xactware as an estimation tool for professional remodelers. According to Xactware, most major insurance companies in the United States and Canada utilize Xactware software for creating window replacement claims (Xactware 2017). The Xact Remodel tool provided unique data regarding consumable materials (e.g., flashing, backer rod, caulk, and spacers) compared to the other tools. Xact Remodel also breaks out bare labor costs from labor overhead burden (i.e., health and unemployment insurance) and profit. The labor rates were used to validate labor costs in the model, and the consumable materials cost was incorporated directly into the final model. 


\subsubsection{RS Means}

The RS Means model provides construction software, data, and services for the construction industry across major sectors and was developed by Gordian (Gordian 2017). For this project, NREL utilized the 2015 Green Building version of the RS Means costs database. Data from RS Means included labor times, labor cost, and labor overhead and profit. Exclusive to the models studied here, RS Means included regional multipliers for labor rates that provided regional differentiation in labor costs. The labor times and regional multipliers were incorporated directly into the final cost model.

\subsubsection{Social Media Invoices}

NREL sought real invoices from past window replacement projects from people internal and external to NREL. These invoices provided actual cost numbers and allowed for validation of the overall window replacement cost. These invoices also provided how cost categories were broken out for consumers on estimates and invoices, which were varied on the amount of information provided. A message was posted to internal NREL sites and several external sites (e.g., Nextdoor, Angie's List, and home improvement forums) for access to invoices. This message can be found in Appendix A. All personally identifiable information (PII) was asked to be removed before invoices were transferred to NREL and none was collected.

\subsubsection{Direct Installer Data}

NREL met with one local installer to collect invoices from past projects (installer asked to remain anonymous for the purposes of data collection). Invoices were provided for three different frame types (wood, vinyl, and aluminum) and included window retail cost, installation price, old window disposal fee, and price of trim install. Invoice data were used to validate the total window replacement cost in the final cost model.

\subsubsection{Industry Organization Data Collection}

NREL partnered with the Energy Efficiency Building Coalition (EEBC) headquartered in Golden, Colorado, to field an over-the-phone questionnaire to EEBC's members. Data collected in the survey were the total cost of window replacement, the percentage of total cost made up by soft costs, and any non-cost barriers to window replacements. The questionnaire can be found in Appendix B. Data received from EEBC do not include company names or other specific identifiable material.

\subsubsection{Direct Industry Outreach}

NREL validated the cost model through direct industry outreach at events and conferences. NREL team members attended two window conferences (American Architectural Manufacturers Association [AAMA] Fall meeting and the National Fenestration Rating Council [NFRC] Fall meeting) to solicit industry feedback. Attendance at these events led to contact with Jim Snyder, ${ }^{2}$ an independent consultant for the windows industry and a former window installer. After NREL's initial creation of the window replacement cost model, Jim Snyder organized a roundtable meeting with three other participants:

\footnotetext{
2 http://www.windowjim.com/
} 
1. Jenny Chase - Content and communications director of Window and Door Dealer's Alliance (WDDA)

2. Tom Higgins -Retired owner of a small, independent window installation company in Denver, Colorado

3. Emily Thompson - Editor in chief of Window and Door Magazine.

A full report of the Windows Roundtable meeting is in Appendix C. Topics included cost model categories, validation of costs and assumptions used in the model, overall window industry barriers, and a path forward for dissemination of results. Key lessons learned from the industry roundtable discussion are detailed in Section 2.3.

\subsubsection{Hardware Retail Cost Analysis}

Three separate analyses were used to validate the window manufacturing or hardware costs. The three different analyses were performed by LBNL, D+R, and NREL independently. The LBNL analysis worked with manufacturers to examine the manufacturing costs for different window component objects (e.g., glass, frame, low-E, and gas fill). The manufactured cost for a doublepaned, low-E window from the LBNL analysis was around $\$ 16$ per square foot.

The $\mathrm{D}+\mathrm{R}$ International analysis performed a secret shopper exercise in which the retail costs of builder grade (new construction) windows were obtained for 10 different window types in Canada. The $\mathrm{D}+\mathrm{R}$ analysis did not include any soft costs but captured the price per square foot of the window hardware cost. The $\mathrm{D}+\mathrm{R}$ analysis found that both single and double hung windows cost around $\$ 25$ per square foot. ${ }^{3}$ The difference between the LBNL analysis and $\mathrm{D}+\mathrm{R}$ analysis was assumed to represent the markup and profit cost for window manufacturers upon sale to window dealers.

NREL examined the retail cost of single and double hung windows through an online search of window products available on both the Home Depot and Lowes websites. Several large metropolitan areas (Seattle, Denver, and Boston) were analyzed to see if regional differences affected window prices. Retail cost per square foot observed was directly in line with the $D+R$ analysis, and there did not seem to be much variation in regional window prices. This lack of regional window price variation confirmed $\mathrm{D}+\mathrm{R}$ 's findings that efficiency metrics did not impact the final retail price.

\subsection{Top-Down Cost-Modeling Data Analysis Results}

This section discusses results of data collected for each of the various data sources detailed above. The total installed cost of replacement windows and soft-cost ratios were used to validate outputs to the cost model. The installed price per window and the soft-to-total cost ratio are presented in Table 1. Histograms for the soft-cost ratio for all data points and without estimation program data points are shown in Figure 5 and Figure 6, respectively.

\footnotetext{
${ }^{3}$ An exchange rate of 0.77 USD to 1 CAN was used for conversion at the time of analysis.
} 
Table 1. Price Per Window and Soft-Cost Ratio of Data Collected

\begin{tabular}{|c|c|c|c|c|c|c|c|}
\hline \multirow[b]{2}{*}{ Data Source } & \multirow[b]{2}{*}{$\begin{array}{c}\text { \# of } \\
\text { Data } \\
\text { Points }\end{array}$} & \multicolumn{3}{|c|}{ Installed Price Per Window (\$) } & \multicolumn{3}{|c|}{ Soft Cost Ratio } \\
\hline & & Mean & Max & Min & Mean & Max & Min \\
\hline Xact Remodel & 57 & 348 & 1,015 & 152 & 0.19 & 0.32 & 0.10 \\
\hline Craftsmen & 88 & 210 & 289 & 131 & 0.25 & 0.30 & 0.21 \\
\hline RS Means & 63 & 474 & 930 & 236 & 0.24 & 0.30 & 0.16 \\
\hline Installer Invoices & 4 & 795 & 984 & 661 & 0.48 & 0.57 & 0.38 \\
\hline $\begin{array}{c}\text { Social Media } \\
\text { Responses }\end{array}$ & 17 & 536 & 940 & 181 & 0.32 & 0.49 & 0.17 \\
\hline $\begin{array}{c}\text { Industry } \\
\text { Questionnaire }\end{array}$ & 20 & 548 & 2,000 & 100 & 0.45 & 0.75 & 0.1 \\
\hline Total & 249 & 485 & - & - & 0.32 & - & - \\
\hline
\end{tabular}

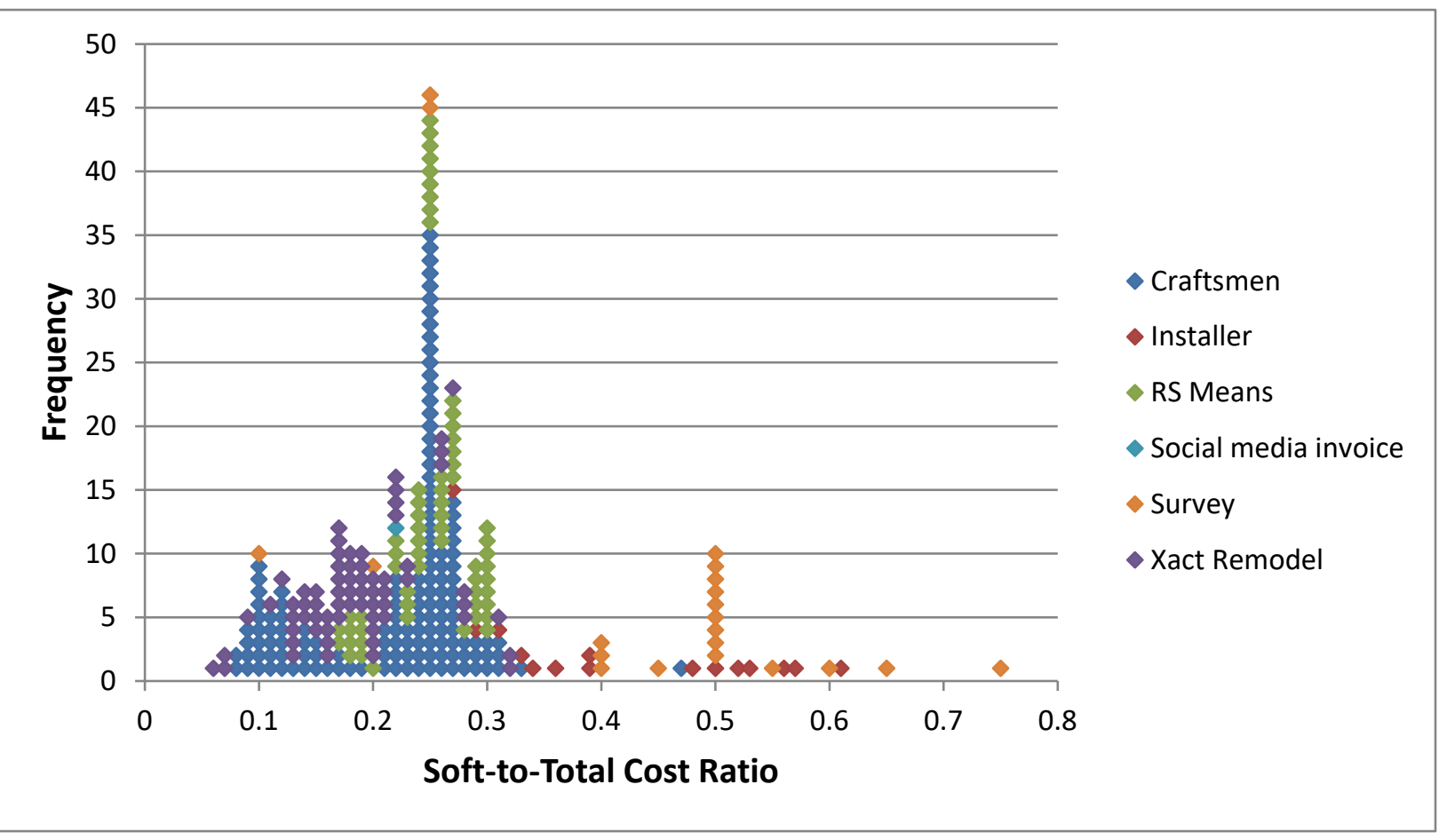

Figure 5. Soft-cost ratio histogram, all data points 


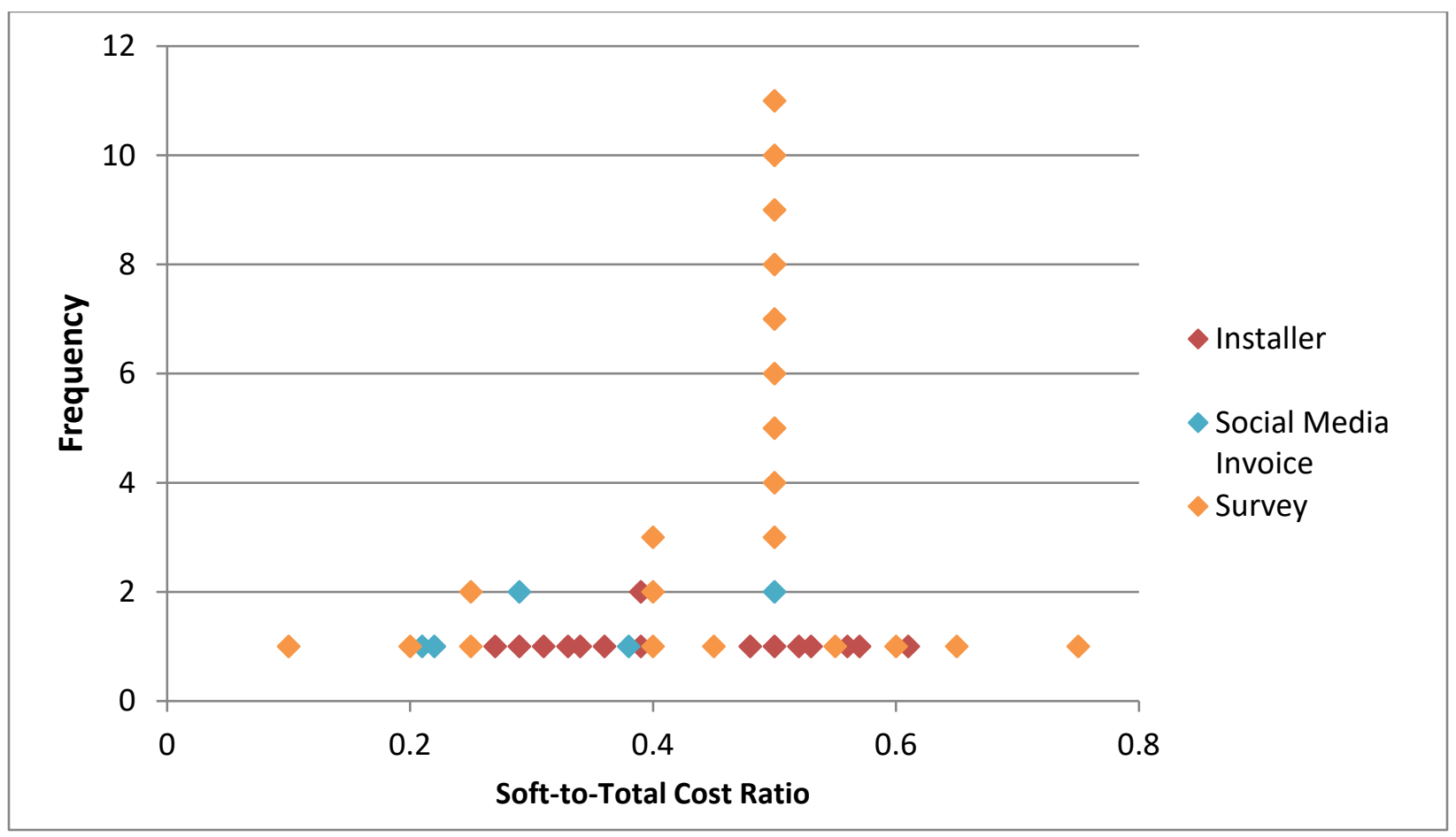

Figure 6. Soft-cost ratio histogram, estimation programs excluded

There are two distinct trends between the estimation software costs and real-life observed prices. The mean values for installed price per window and soft-cost ratio for the estimating programs were consistently under the values found in the invoices collected. The mean cost of window installation was $\$ 485$ per window for all data, and when the estimation programs were excluded, the mean jumped to $\$ 570$ per window (an 18\% increase). The difference in total cost between estimation programs and invoice collection is likely due to exclusion of costs such as company overhead, customer acquisition, and other miscellaneous costs (e.g., inventory and shipping) in estimation programs. This difference is also consistent with the soft-to-total ratio observed. The average soft ratio of all data points is 0.32 , while the average soft-cost ratio is 0.42 when the estimation programs are excluded.

One thing worth noting is that the insurance industry standard for compensating installers during window claims is calculated using the Xact Remodel tool. The installed price per window was closer than the other estimation programs to the collected invoices but still below real-life estimates. This observation was confirmed by one installer who said they avoided insurance claims jobs due to the low payment price per window replacement.

\subsection{Key Learnings from the Industry Roundtable Meeting}

The full results from the industry roundtable discussion are reported in Appendix C. This section will detail the main qualitative points that NREL identified during the meeting. Part of the roundtable meeting detailed model inputs and industry structure, but a large part of the meeting discussed non-cost barriers to increased window replacements. The key learnings presented here are split up into separate categories, as identified by NREL. These categories are: marketing, model and industry data, window market insights, and industry identified needs. Each section below will detail the top learnings from each section. 
Note that these learnings were identified by our participants, but this may not be indicative of the entire window industry or other individual installers. One comment from the meeting was "If you asked five different companies what the largest barriers to window deployment are, you would likely get five different answers." However, these key learnings were validated through other industry interactions.

\subsubsection{Marketing}

- The cost of marketing represents 5\%-20\% of business operating costs. Sales/lead generation expenses make up a large portion of those business operating costs.

- Consumer priorities during sales are (1) energy efficiency and (2) comfort.

- The "sticker shock" of the large upfront cost of window installation causes consumer discomfort and decision paralysis when the installer tries to sell more efficient and expensive windows.

\subsubsection{Model Inputs and Industry Data}

- The prototypical window for modeling should be a "vinyl, box frame insert replacement into an existing wood frame," as this makes up a large part of the window replacement market, according to the two installers present.

- Potential drivers that could increase window replacement cost are previous frame conditions, window access (second story), and rough opening types (e.g., wood and brick).

\subsubsection{Window Market Insights}

- Overall, the window market is very competitive. There are a variety of different window products, housing materials and installation scenarios, and companies. The individual costs broken out by cost category vary a lot, but the total replacement costs are comparable between installers.

- Costs are often 10\%-20\% higher from smaller installers compared to big window companies. These higher costs may be offset by a higher quality install and product, but this must be sold to the consumer due to competitive industry pricing.

- For small installers, an average gross profit of $40 \%$ per project is needed to stay in business long term. This profit is needed to cover the overhead costs associated with customer acquisition and other SG\&A costs.

- Insurance industries use Xact Remodel for compensating insurance claim installations, but payment provided through the software is lower than needed to sustain smaller companies. One installer would often reject insurance jobs due to low profit margins.

- The installation industry is made up of mostly smaller ("Mom and Pop") companies, but there are wide variations in company size across the window supply chain. For example, the top 100 manufacturers identified by Window and Door Magazine have a range of annual revenue from $\$ 15$ million to $\$ 1$ billion (Window \& Door Magazine 2016). 


\subsubsection{Industry-Identified Needs}

- The largest barrier identified during the roundtable was lack of consumer education regarding quality window products and installation. Increased consumer education can benefit both consumers and industry by reducing upfront decision paralysis and allowing consumers to make fiscally rational decisions.

- Consumers need to know they are getting a good deal through independent, credible sources.

- Consumers need information regarding quality installation procedures and contractors. Installation certifications are in development by large industry organizations, but many small installers do not participate in these organizations and consumers do not currently know about certifications or their value.

The next section will outline inputs to the cost model and the data source used for each. 


\section{Model Inputs and Sources}

Similar to the analysis methodology used by Fu et al. (2016), NREL created a bottom-up cost model for window installation. For each of the individual cost categories, NREL compiled mean costs from the data sources above. These average costs were incorporated into the cost model and then validated with industry input. The cost categories, data sources, and how these cost categories are represented in the model are shown in Table 2.

Table 2. Cost Category Sources in the Cost Model

\begin{tabular}{|l|l|l|}
\hline Cost Category & Source(s) & Representation in Model \\
\hline $\begin{array}{l}\text { Hardware (manufactured) } \\
\text { cost }\end{array}$ & LBNL manufacturing model & $\begin{array}{l}\text { \$/sq. ft manufactured cost from } \\
\text { model }\end{array}$ \\
\hline Dealer profit & $\begin{array}{l}\text { D+R Canadian window retail } \\
\text { secret shopper analysis, U.S. } \\
\text { window retailer online survey }\end{array}$ & $\begin{array}{l}\text { Dealer profit calculated by } \\
\text { subtracting average retail price from } \\
\text { LBNL-modeled manufactured cost }\end{array}$ \\
\hline Installation & $\begin{array}{l}\text { Labor productivity rates: } \\
\text { estimation tools; labor cost: } \\
\text { Bureau of Labor Statistics (BLS) } \\
\text { data; RS Means }\end{array}$ & $\begin{array}{l}\text { Labor time multiplied by labor } \\
\text { wages }\end{array}$ \\
\hline Labor overhead and profit & $\begin{array}{l}\text { RS Means, BLS data, David } \\
\text { Bacon }\end{array}$ & $\begin{array}{l}\text { Multiplier from wage data; includes } \\
\text { labor insurance, benefits, and profit }\end{array}$ \\
\hline SG\&A expenses & $\begin{array}{l}\text { BLS wage data, estimated small } \\
\text { and large company sizes }\end{array}$ & $\begin{array}{l}\text { Built company size and wages } \\
\text { within model; SG\&A cost allocation } \\
\text { based on set number of windows } \\
\text { installed per year }\end{array}$ \\
\hline Shipping & $\begin{array}{l}\text { Data from previous solar analysis } \\
\text { (Fu et al. 2016) }\end{array}$ & $\begin{array}{l}\text { Assumed time for window pickup, } \\
\text { travel, and setup per job site }\end{array}$ \\
\hline Sales tax & BLS data & Tax data pulled from state tax table \\
\hline Permit cost & $\begin{array}{l}\text { Price compiled from average of } \\
\text { fo municipalities' permitting costs } \\
\text { for a window project of \$5,000 }\end{array}$ & Industry validated \\
\hline Contingency & Flat fee: 3\% of total project cost \\
\hline
\end{tabular}

The data above were entered in to the cost model for various window types and projects. The next section details inputs needed for the cost model along with final outputs for an example project. 


\section{Window Replacement Cost Model Results}

NREL created a cost model that allows the user to enter relevant project data to calculate the cost of a window replacement project. The user can input the following into the model for variation of final project costs:

1. Location - Changing the location will pull relevant state taxes from BLS and statespecific labor multipliers supplied by RS Means. This allows the model to incorporate geographic differentiation.

2. Labor payment rates - User can choose between three different modeled labor rates: BLS, RS Means, and Davis-Bacon. BLS labor rate data were used as the default during modeling.

3. Year - The year accounts for inflation in labor rates.

4. Company size - The user can choose between small, regional installer and large, national installer. Each company utilizes different SG\&A expense schemes, and the model will calculate different SG\&A costs between the two.

5. Window type and size - The user can choose different window types and sizes that will change the manufacturing cost and the amount of time to install the window. Choices are preprogrammed into the model, and the user just needs to pick the relevant operator type and window size. Options available are (with the data source in parenthesis): vinyl single hung (Craftsmen), vinyl double hung (RS Means), vinyl replacement (Craftsmen), and vinyl casement (RS Means).

6. Contingency - The user can set different contingency rates based on the project. A default value of $5 \%$ is used in the model based on inputs from PV cost modeling.

7. Window quantity - The user can estimate the overall project cost of installing multiple windows.

The main costs, inputs, and outputs are shown in Figure 7. 


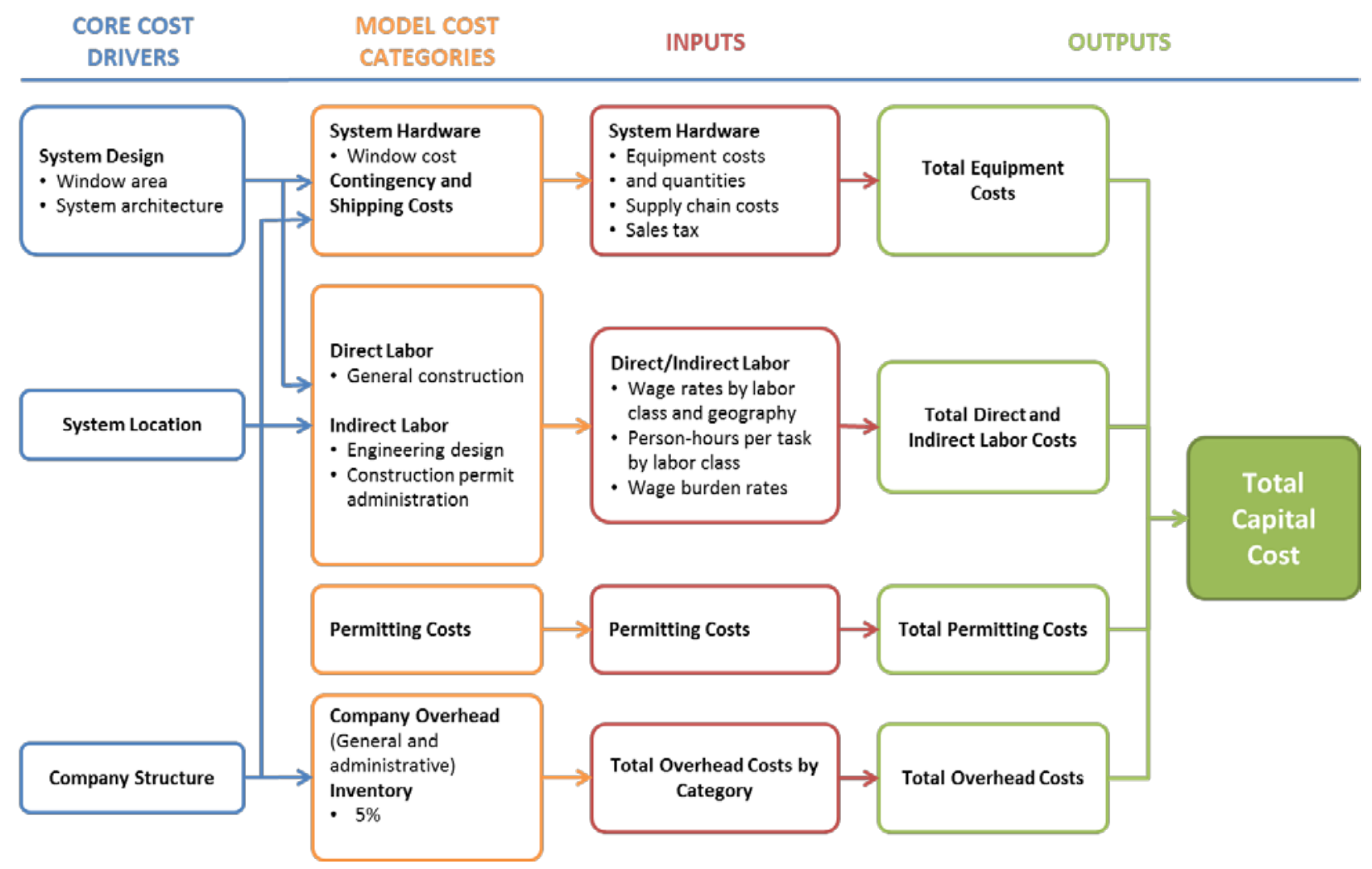

Figure 7. Cost drivers, modeled cost categories, inputs, and outputs of window replacement cost model

After the user finalizes all inputs, the model will update to reflect the overall project cost. Costs by category are shown in Figure 8 . This figure represents economies of scale available if more windows are installed per project. As shown in Figure 8, window materials make up roughly $55 \%$ of the total installed cost of the window. The soft-cost ratio is in line with observed softcost ratios from installer invoices. Note that there were not enough verified data points for the various window components to be able to provide error bars for the figure. The figure is based off available data and the overall magnitude of the numbers were verified by industry members.

Labor cost (direct install labor, labor overhead, and company overhead) make up the next largest cost category. At a high number of windows per project (10), the total cost per window is roughly $\$ 600$ per window. This number is high compared to the total data set average ( $\$ 485 /$ window) but is in line with the weighted average seen from actual installer data (\$570/window). The cost model is included with this report in an Excel workbook. 


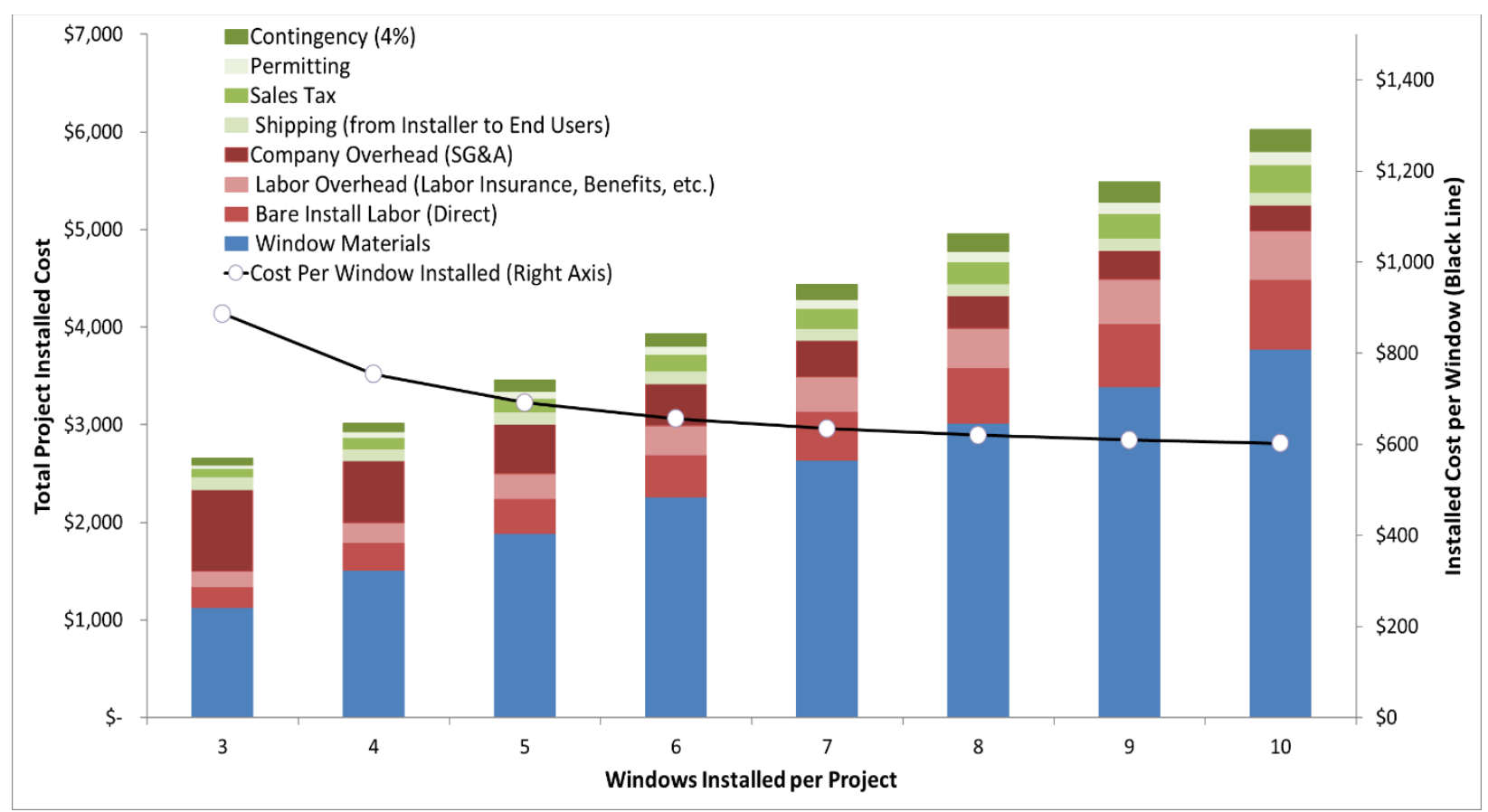

Figure 8. Installed cost per project for a small installer, by cost category ${ }^{4}$

\subsection{Caveats}

During data collection, NREL was not able to collect cost data on every individual cost category represented in the model. Outside of sales tax, every category was based either on previous models or industry representations (e.g., company size and project contingency). However, installed costs per window and the soft-cost ratios observed from previous projects were used to validate the final model output. The model does not represent individual project conditions but seeks to capture averages across the industry. Many items outside of the model may impact project cost directly, which are discussed in Section 5.1.

\footnotetext{
${ }^{4}$ This figure represents the cost components of a small window installer that installed 2,000 windows per year. Hardware costs are in blue, costs associated with labor are in red, and all other miscellaneous soft costs are in green. Dealer profit is included in the manufacturing cost, and installer profit is built into SG\&A costs.
} 


\section{Data Analysis}

\subsection{Cost Insights}

\subsubsection{Variations in Window Replacement Cost}

During discussions with industry members at conferences and the windows roundtable, several items were identified as cost drivers that could cause variation in the total cost of window replacement. Although not an exhaustive list, items identified were:

- Age of home - Lead paint can be a concern in homes built prior to rules instituted by the U.S. Environmental Protection Agency (EPA) in 1978. ${ }^{5}$ By law, a homeowner must disclose if the house was built before 1978 or if there are any concerns with residual lead paint before work can commence. If there is a concern, the window installer must perform a test to see if lead paint was used around the window frame. If lead is found, procedures must be followed that will add to the total installed cost. These procedures will seek to contain dust and debris from the job area and increase ventilation to limit exposure (EPA 2011). For a large window project, the EPA estimates that the incremental cost to the project will be between $\$ 124$ - $\$ 376$ for the entire project, or 2\%$6 \%$ cost increase per window (EPA 2014). However, from examination of consumer sites (i.e. Angie's List), this number may be closer to $\$ 130$ per window (roughly $20 \%$ cost increase per window) and require 30-40\% more labor time (Barrineau 2017).

- Initial build quality - The installed condition of the previous window, frame, and sill can impact the total job cost due to increased effort to install the product correctly. If the sill or frame is rotted out, then the impacted piece should be removed and addressed to prevent further rot and ensure energy savings. If insulation was left out or installed improperly around the window, further work is needed to ensure that the installed window meets performance standards. Adding insulation can be a fairly inexpensive repair, but replacing a rotted out window frame may add roughly $\$ 200-\$ 600$ (33\% $100 \%$ cost increase) per affected window (Improvenet 2016).

- Building materials - Building materials around the window frame can impact the final installed cost of replacement. Wood frames will lead to higher cost associated with trim after installation. Wrapping the brick mold casing around each window will lead to additional time and cost per window.

- Physical access - Windows installed above the ground floor will require equipment to reach the window and safety measures for working at heights. This extra equipment increases labor time for setup and cause an increase in the cost of window replacement. Anecdotal evidence shows that the difference in cost from windows installed on the ground floor and the second story is roughly $\$ 50-\$ 130$ per window $(10 \%-20 \%$ increase in window cost) (Rempros 2018).

- Size of job - The cost of initial project setup, disposal of previous windows, and cleanup is similar across jobs of all sizes. More windows installed per project allow for this cost to be burdened over all the windows replaced, leading to a lower installed cost per

\footnotetext{
${ }^{5}$ https://www.epa.gov/lead/lead-residential-lead-based-paint-disclosure-program-section-1018-title-x
} 
window. Some installers mentioned that they would only take jobs of certain sizes due to this flat cost for all projects.

- Job quality - One differentiation of cost identified by industry is quality product installation. Extra steps to ensure the window is installed properly can lead to higher labor time per window and, therefore, higher installation cost. However, this cost can be offset by increased energy savings over the life of the window. Effort is needed to explain this extra cost to the consumer and may impact the customer acquisition costs.

Each project will vary in total cost to the installer, but because the window replacement market is competitive, the average cost to consumers will be similar over many projects. The cost of laborintensive projects will need to be balanced with "easy" projects or higher costs may be passed onto the consumer. Maximizing the number of windows per project will offset these variable costs across many windows, but this is not always possible.

\subsubsection{Cost Estimation}

There was no standard way of presenting job/cost information during upfront estimation observed from the invoices collected. This variation caused difficulty in comparing the soft costs of different projects. Overall project estimates and installation costs were presented in the following ways:

- Total project cost - Some installer invoices included cost estimation for labor and windows in one total price, and only the overall project cost was presented to the consumer on the invoice.

- Flat fee per opening - Some installers charge a flat fee per opening regarding removal and disposal of the old window and installation of the new window. Trim options were an extra charge on these invoices. The invoice presented the hardware cost of each window installed and then broke out the flat fee of installation.

- Installation broken out as a separate line item - Installers presented an installation fee as a line item for all windows to be replaced. There was no breakout of timing or different installation costs for individual windows.

- Installation included with window price - Installers presented the cost of installation within the cost of the window itself. In these cases, installation was billed to be "free" to the consumer even though the cost of installation was included in the price.

Other variations in invoices included a small fee for setup and disposal. In others, this fee was included in either the labor charge or overall estimate. Some invoices contained a discount on either the overall project cost or on individual windows themselves. The discounts encountered were based on window promotions, volunteer activities, and veteran discounts. A few invoices presented either the projected energy savings or included the NFRC label on the invoice, but most invoices collected did not contain this information. The variation of cost estimation and invoice preparation can contribute directly to decision paralysis of consumers. Consumers do not know if they are getting a good deal, and often it is hard to compare among potential installers.

In talking to industry members, companies have different sales tactics and invoice presentations aimed at getting the customer to replace their windows. This is in line with other findings of 
customer acquisition costs and success rates of converting sales leads to installation being a large barrier to increased deployment.

\subsubsection{Permit Variation}

Permit information and cost for window replacements was highly variable by jurisdiction and often hidden within building codes. After a cursory online search, the NREL analysis was able to find 20 jurisdictions that readily published fees for building permits related to window replacement. These jurisdictions were spread out all over the country in different regions, but a few were either in the same state or neighboring jurisdictions within the analysis, which allowed for some comparison. Most jurisdictions only required a permit if the egress of the window was being changed, but some required a permit if the project was over a certain dollar amount or over a certain number of windows replaced. However, many jurisdictions do not require a building permit if the window installed is "replace-in-like-kind."

Permit fees observed were based off various project details including percentage of total project fee, flat fee up to a certain dollar amount, fee based on number of windows replaced, estimated square feet of the project, or a combination of previous options. There were no geographical similarities between permit fees or requirements found, and two jurisdictions that abutted one another presented different requirements. This difference in permit fees is shown in Figure 9. In this figure, NREL calculated the permit fee for a project that replaced nine windows and cost $\$ 5,000$ in different municipalities. The mean amongst the 20 municipalities observed was $\$ 110$ per project, shown by the red line in the figure, but there was significant variation.

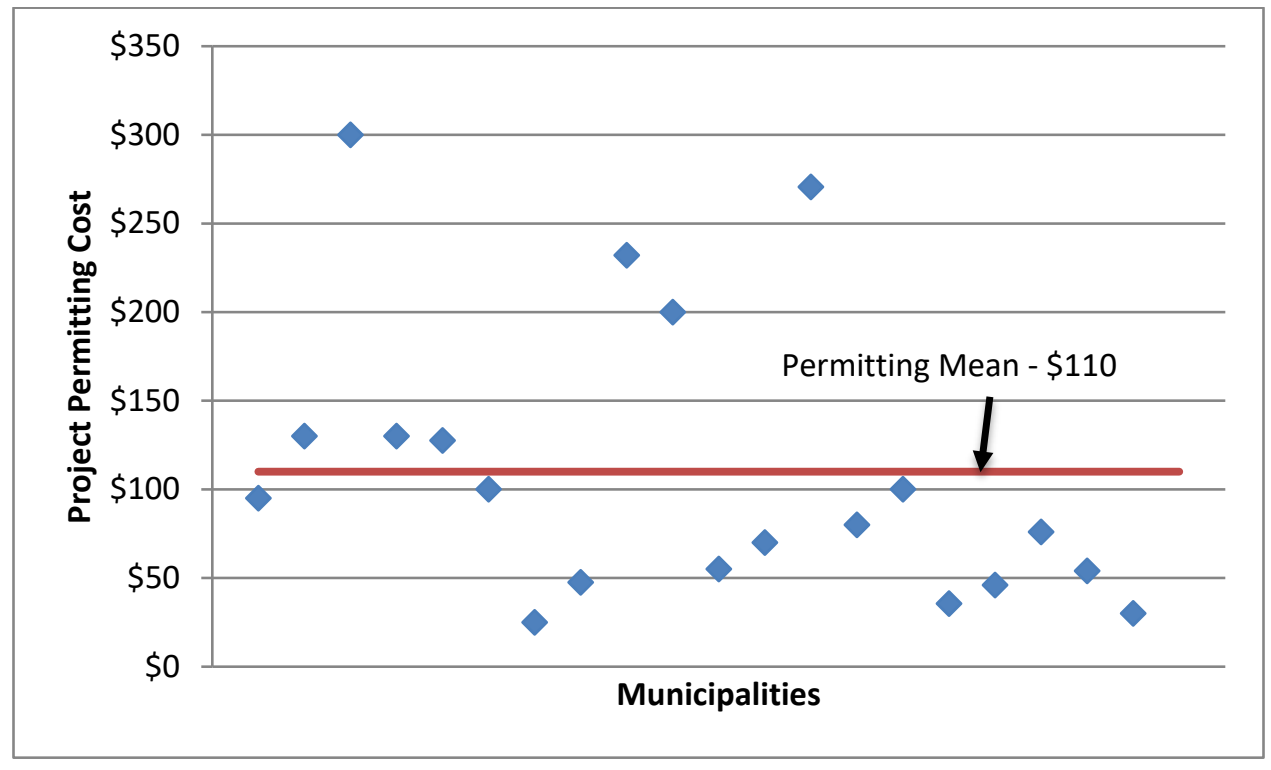

Figure 9. Building permit cost for different municipalities for a $\$ 5,000$ project $^{6}$

During industry round table discussions, installers identified issues caused by variations in building permitting requirements as many local installers operated in multiple municipalities.

\footnotetext{
${ }^{6}$ Municipalities are arranged in alphabetical order based on data availability.
} 
Finding these requirements on local websites and staying up to date on building code changes is difficult but important to ensure compliance with local building codes.

\subsection{Non-Cost Barriers Identified}

NREL did not observe a single, significant cost driver that impacted the adoption decision of consumers to replace their windows. However, industry members identified several non-cost barriers to window replacement, mostly around the reduction of upfront customer acquisition. These efforts include increased consumer education regarding window replacement costs, benefits, and options and helping consumers identify quality products and installation. Note that the non-cost barriers presented here are identified by industry members. If consumers were interviewed, they may come up with partially or completely different drivers. Consumer interviews were outside the scope of the project and will not be discussed further in this section.

\subsubsection{Consumer Education}

Industry members identified a lack of upfront, credible information sources as a barrier to increased window replacements. Having to educate individual consumers during the sales process increases the burden and cost of upfront sales and acquisition. Industry members posit that educated consumers will be more likely to understand window replacement options available and the value of replacing the windows (discussed in the next section), both from an energy saving and non-energy saving perspective, leading to more window replacements.

One remaining question with consumer education is who should be responsible for creating educational materials and how these educational materials should be organized, branded, and distributed to consumers. Industry members said that materials branded through credible, independent agencies have been successful in the past, such as the Efficient Window Collaborative (EWC) website. The EWC seeks to "provide unbiased information on the benefits of energy-efficient windows, descriptions of how they work, and recommendations for their selection and use" (Efficient Windows Collaborative 2017). Industry roundtable participants mentioned that the EWC website was a good source of information to provide during the sales process to ensure consumers were getting a quality product.

During the industry roundtable, participants also mentioned that the national laboratories' expertise and branding could be used to provide a credible informational source to customers. Participants said that national laboratories were nationally recognized by consumers, and their independent nature could provide a credible source of information. During the Building Technologies Windows and Envelope Roadmap Workshop, industry members discussed using industry trade organizations (e.g., AAMA, NFRC) and their extensive networks to get the educational materials out to consumers. Members identified value for consumers hearing the same message from industry members, no matter which installer, distributor, or manufacturer they talked to. A consistent message could provide credibility of information distributed through industry and reduce some upfront decision paralysis.

\subsubsection{Value Versus Cost of Window Replacement}

A large barrier identified through the industry roundtable discussion was the initial upfront ("sticker shock") cost of a full home window retrofit. Any additional cost for higher energy efficiency products can potentially reduce customer adoption. However, a high efficiency 
window with a large upfront cost may yield benefits to consumers from increased energy savings and comfort over the life of the product. Also, windows are a large cost item that consumers will only purchase a few times in their life, making the upfront decision process uncomfortable. Due to this "decision paralysis," consumers may choose to not replace their windows because doing nothing is the easier choice.

The premium cost of energy efficient products needs to be justified to consumers during the sales process along with the initial large upfront replacement cost. Installers often try to sell this premium based off energy efficiency savings but calculating these savings can be difficult with current tools. Energy use is highly dependent on the in-situ energy efficiency rating of the house, ambient temperature, and home user traits (e.g., leaving windows/doors open and temperature set points). One industry member noted that modeled energy savings were only accurate if an entire home retrofit occurred. Upgrading one product could possibly lead to energy losses elsewhere in the house due to increased infiltration/exfiltration through unrepaired defects. Outside of energy savings, comfort is a secondary sales point for higher efficiency products, but placing a rating on this is highly subjective to individuals and may be hard to notice, depending on the current product installed. Education of the cost and benefits of energy efficient products can allow consumers to make rational decisions and reduce some of the upfront sales burden during the customer acquisition process.

\subsubsection{Identifying Quality Products and Installation}

Currently, no installation certifications or standards are available and recognizable by consumers to ensure a quality installation. Correct installation of an energy efficient product is the only way to ensure performance and energy savings. Large trade organizations are in the process of creating installation certification and training programs, but one installer mentioned that many of the small installation companies, which make up a large portion of the installation market, do not participate in these organizations.

Both the ENERGY STAR ${ }^{\circledR}$ program and NFRC label were lauded by industry for assisting the sales process in identifying energy efficient products. This allows for communication of energy benefits to offset increased costs. However, industry members mentioned that sales people and consumers do not fully understand NFRC label items and what values are desirable during sales. Coupling window performance labeling and installation standards can convince consumers that they are receiving quality products that will perform up to the energy efficiency ratings that window products claim. 


\section{Conclusion}

This paper detailed data collection and cost-modeling efforts to understand the hardware and non-hardware (soft) cost of residential, energy efficient window replacements. NREL created a bottom-up cost model that details costs associated with window materials, installation labor, company overhead, and administrative costs. NREL did not find a single cost area for improvement but observed several non-cost barriers to increased window replacements. The industry identified, non-cost barriers associated with window replacements are consumer education, lack of communication of the value of window replacement to consumers, and difficulty for consumers to identify quality products and installation. However, consumers may identify different non-cost barriers associated with window replacements. 


\section{References}

Barrineau, Trey. 2017. "Lead Paint and Window Replacement: What You Need to Know." Glass.Com. July 21, 2017. https://info.glass.com/lead-paint-window-replacement/.

Catalina Research, Inc. 2016. "First Look: Windows." www.catalinareports.com.

Efficient Windows Collaborative. 2017. "Efficient Windows Collaborative | Home.” 2017. http://www.efficientwindows.org/.

EPA. 2011. "Steps to Lead Safe Renovation, Repair, and Painting." https://www.epa.gov/sites/production/files/2013-11/documents/steps_0.pdf.

_. 2014. "Rennovation, Repair, and Painting (RRP) Rule." https://www.epa.gov/sites/production/files/2014-09/documents/full_rrp_fqs_august_11_2014.pdf.

$\mathrm{Fu}$, Ran, Donald Chung, Travis Lowder, David Feldman, Kristen Ardani, and Robert Margolis. 2016. "US Solar Photovoltaic System Cost Benchmark Q1 2016." NREL/PR-6A2066532. Golden, CO: National Renewable Energy Laboratory (NREL).

Gordian. 2017. “About Us | RSMeans Industry Data.” 2017. https:/www.rsmeans.com/info/contact/about-us.aspx.

Grant Communications. 2017. "RIVCO Double-Hung and Casement Window Diagrams.” 2017. http://www.rivcowindows.com/rivco-window-diagrams.php.

Improvenet. 2016. "2018 Window Frame Repair Cost | Window Frame Replacement." December 2016. https://www.improvenet.com/r/costs-and-prices/window-frame-repaircost-estimator.

Pella. 2017a. "Full Frame Replacement Window Frame Type." 2017. http://www.installpella.com/windows/fullframereplacement. . 2017b. "Pocket Replacement Window Frame Type.” 2017. http://www.installpella.com/windows/pocketreplacement.

Rempros. 2018. "Windows Installation Prices - Cost to Install or Replace a Window." 2018. http://www.rempros.com/installation-prices/how_much_install_windows.html.

Window \& Door Magazine. 2016. “Top 100 Manufacturers 2016." March 12, 2016. https:/windowanddoor.com/article/marchapril-2016/top-100-manufacturers-2016.

Xactware. 2017. “About.” 2017. https://www.xactware.com/company/about\#. 


\section{Appendix A: Social Media Outreach Message}

\section{Do You Have New Windows? CEMAC Needs Your Help!}

Did you recently replace the windows in your home? If so, you can help advance research that could reduce the cost of replacement windows.

The Clean Energy Manufacturing Analysis Center at the National Renewable Energy Laboratory is studying the costs of installing energy-efficient windows in homes-from the cost of the windows themselves to costs for installation and labor - and we're collecting as much data as possible. We are searching for copies of actual invoices from energy-efficient window installations.

We are particularly interested in receiving invoices that break out the cost of the windows from the installation costs, but invoices that show total costs will also be helpful. Our team is only interested in cost information and wants to ensure your privacy is respected; please black out any personal information and submit your invoice to Catherine Burke [Catherine.Burke@nrel.gov].

This research is being done as part of the U.S. Department of Energy Clean Energy Manufacturing Initiative for the Building Technologies Office. More information about CEMAC can be found at http://www.manufacturingcleanenergy.org/

Please contact Maggie Mann [margaret.mann@nrel.gov] with any questions. 


\section{Appendix B: EEBC Questionnaire}

In support of its mission to inform policy and investment choices that promote the transition to a clean energy economy, the Clean Energy Manufacturing Analysis Center (CEMAC) is working to help the DOE enhance its understanding of the "soft costs" of energy efficient window retrofits. Soft costs are all non-window components of total installed costs, such as permitting fees, engineering (such as window selection and analysis of energy savings), customer acquisition, installation costs, and associated materials like insulation and trim.

Your support will help CEMAC and the DOE measure the soft costs associated with energy efficient window installation. This effort seeks to understand soft costs to identify areas where cost can be reduced to promote window installation and to inform future work or research opportunities. This questionnaire will assist in the data collection portion of a report to be released in the fall of 2017.

This questionnaire should take approximately 20 minutes to complete. All cost data provided will be completely anonymous and will be shared only in aggregated form such that individual company data are not discernible.

Assume a one-story, single-family residence in your primary geographic area of operation. Please provide a typical range of total installed costs for a single vinyl window retrofit of the assumed residence.

- Of the total installed costs, what percentage is the cost of the windows?

- Of the non-window costs, what are the primary cost categories in your region? If possible, please provide an approximate breakdown, such as $40 \%$ - Category A, $40 \%$ Category B, 20\% - Category C.

- What factors have you noticed that significantly raise or lower the non-window portion of total installed costs?

- If willing, please share 2-5 past customer invoices. To ensure confidentiality, please remove any customer information such as name and phone number before submitting. To help understand any possible geographic differences in soft costs, please leave the zip code of where the work was completed.

- Choose the region that best describes your company's primary area of operations: (1) Southwest, (2) Northwest, (3) Midwest, (4) Northeast, or (5) Southeast.

\section{About CEMAC}

CEMAC provides objective analysis and up-to-date data on global clean energy manufacturing. Policymakers and industry leaders seek CEMAC insights to inform choices to promote economic growth and the transition to a clean energy economy. http://www.manufacturingcleanenergy.org/ 


\section{Appendix C: Windows Roundtable Summary Windows Roundtable Discussion Writeup}

Participants in the roundtable discussion were:

- Jenni Chase, content and communications director of WDDA

- Emily Thompson, editor in chief of Window and Door Magazine

- Tom Higgins, owner of local independent window installation company (retired)

- Jim Snyder, writer, consultant, trainer, and speaker for the fenestration industry (windowjim.com)

- $\quad$ Ran Fu, Maggie Mann, James McCall, and Rob Tenent, NREL.

Major Takeaways $\underline{?}$

Marketing

- The cost of marketing represented 5\%-20\% of business operating costs, with sales and lead generation making up a large portion of the operating costs.

- Consumer priorities (identified by industry members) are: (1) energy efficiency, (2) comfort.

- There is a "sticker shock" of how expensive window installation can be and these costs occur all at once. Additional hardware costs for more efficient window products can increase this shock.

- Calculating overall energy savings can be difficult due to:

○ Shifting energy losses through other inefficient building products (i.e. doors, windows) if a full retrofit does not occur

$\bigcirc \quad$ Varied living habits (entry and exit of house) and temperature profiles

- As of 15 years ago, the cost of a qualified lead was $\sim \$ 250$ with a roughly $25-33 \%$ success rate. Internet marketing decreased this cost to $\$ 150$ per lead.

Installation

- Dealers are retail companies that are customer facing - the middle person between the windows manufacturer and the installer (often subcontracted).

- Plans to stay long term in a house is a large driver for window replacement. Because of this some installers focus marketing efforts on older customers.

- Most installations are insert replacement windows and full frame window replacement has a different meaning to different industry members.

\footnotetext{
${ }^{7}$ Items in bold were determined to be important takeaways from the meeting, as determined by the project team.
} 
- Insert replacement windows (into existing wood frame) represent a majority of the window replacement market.

- Replacement products include:

- Flush fin - installed into original aluminum frame; does not seal well, so it is usually used on the west coast where there is a moderate climate and it is not overly rainy

O Insert - insert window is a premanufactured window unit with its own frame that gets installed into existing wood from, thereby reducing window glass area

- Sash kit - replaces one section of a single or double hung window and does not require removing old window.

- Industry members identified "vinyl, box frame insert replacement into wood frame" as the prototypical window to focus on in the analysis

- The manufactured cost of a 4'x4' window is $\$ 250$ (per one installer).

Model Data

- In small companies, sales associates generally do not charge time and cost to project, but their cost is included in the profit margin.

- Example labor rates: \$25-\$30/hour with window installation taking 1-1.2 hours per window. Replacement crews will generally install 8 windows per day.

- Using a contingency of $4 \%$ is close to industry standard. Contingency is included in the window cost and often will cover warranty issues

- Manufacturer binders can be a good source for manufacturer prices and add-on cost

- Required to be published by the U.S. Federal Trade Commission (FTC) because the consumer has a right to prices

- Potential additional cost drivers identified were:

○ Wrapping the brick mold casing — not included with normal installation cost

○ Window access - ground floor vs $2^{\text {nd }}$ floor

○ Previous frame type being replaced - more cost for wood finishing

- Average replacement job is roughly $\$ 10,000-\$ 12,000$ in total cost with roughly 10-16 windows replaced, depending on house type.

- Roughly 200 jobs per year (\$2 million in sales) is common for a small installer.

- New windows are often shipped to wholesalers or dealers and manufacturers generally require some physical showroom/space to deliver product.

○ Storage/showroom space needed is cheaper than normal retail operations but needs to be included in inventory cost. 
- Cost of installation labor is roughly $\$ 100-120$ per window (which includes disposal fee) in the Denver market. This is consistent with labor productivity and prices in model.

- Contractor is generally responsible for obtaining permit and this fee is tacked onto job total at the end. Consider using a fixed cost for permitting in the model.

Market Insights

- There was a large consolidation of window manufacturers/installers recently after the economic downturn.

- For small companies, there is a need for at least $40 \%$ gross profits to stay in business long term.

- This value is useful for checking SG\&A costs in model.

- Most installation jobs are performed by small (Mom and Pop) companies with 5 to 10 employees. Job types at these companies: executive assistant, marketer, "gopher," owner, sales

- Supply chain of window installation include small/large window manufacturers, dealers, sellers, and installers.

- Top 10 manufacturers' revenue ranges from $\$ 15$ million- $\$ 1$ billion.

- Small manufacturers path to market is generally through direct sales and generally, they utilize their own subcontractors for installation.

- Dealers are made up of different market strategies. Some only work with architects and specialty applications, while some have their own installers (either employee or subcontractor).

- Insurance industries use Xactimate for compensating installers, but payment is much lower than needed for a sustainable industry; one installer would often reject insurance jobs.

- Overall, the market is competitive, and pricing is important.

- Quality is the differentiation for smaller companies from larger companies who can achieve cost savings through economies of scale (roughly $10 \%-20 \%$ cost savings).

- The Energy Windows Collaborative (EWC) website is considered a success in the industry and assists in the sales process.

- Building codes have a direct impact on market availability of products and change in requirements can cause a change in window cost.

- There is large variety in industry - "If you asked five different companies what the largest barriers to window deployment are, you would get five different answers"

- A large number of different business models are seen in industry.

- Currently, no "market supply chain" or "market ecosystem" analysis exists to compare different products and installers. 
- The window market is very competitive. There are a lot of different window products, housing materials and installation scenarios, and companies so the actual cost breakdowns vary a lot, but the total installed costs are mostly the same. Costs are higher from smaller installers compared to big window companies (maybe 10\%-20\% higher), but these higher costs "usually" represent better quality installation and maybe even windows.

- Windows installed are mostly U.S. manufactured products, but some Canadian products may be in northern states

- Local, small manufacturers have advantage due to reduced shipping costs but do not have access to larger markets.

Industry Needs

- Education of consumers was cited as the largest barrier.

- The NFRC label is good, but consumers need to know what different metrics mean on the label.

- Education efforts benefit both consumers and installers, while publishing costs only benefits consumers.

- One repeated comment "How to convince consumers they are getting a good deal?"

$\circ$ There is a need for independent, credible sources for verification of cost and performance and independent tools to show consumer what realistic costs are.

○ How do you legitimize the high upfront price of installation?

○ Is there some potential for a "basic windows information" sheet from government agencies?

- Air leakage testing of windows is either not done or not disclosed. This is currently not part of the NFRC label and will have a large impact on "comfort" rating (\#2 identified reason for replacing windows).

- There is a need for installation standards or certifications across the industry.

- Currently, installation standards are being developed by industry organizations but may not reach wide audience due to bureaucracy (small companies that represent large portion of market are often not involved).

- Certification program for installers is very important, but the value has not been established to consumers.

- ENERGY STAR rebates were one reason for large penetration of ENERGY STAR products into the windows market

O There is potential industry value in long-term rebates and standards

- Rebates were impactful for getting more ENERGY STAR windows installed. Without rebates, there is not funding going into the development of new products. When rebates came out, there was a huge surge in the industry, but when the 
rebates went away, demand dropped. Consistency in the details of the rebate program over a long period of time is important.

- A customer communication checklist may be valuable to create a script to educate customers of the product

- More transparent data on municipal codes and standards should be published as there is large variation between municipalities and changes to code are often not communicated well

- Codes can have a large impact on cost and not easily available (especially when changed)

- Industry suggestions for DOE funding next year: help industry standardize costs and help customers to understand price of installation.

Study Recommendations

- Bring up discussion of quality (i.e., Why should people go to dealers and installers rather than Home-Depot-type chains?).

- Stay away from publishing cost numbers and instead focus on what cost considerations are encountered

Could end up driving consumers to low-cost, low-quality installers and could lower dealer profits.

- How to address difference in "value of window versus cost?" 